\title{
KINETICS OF HYDROGEN SEPARATION FROM REFINERY OFF-GAS
}

\author{
Abbas Khalaf MOHAMMAD, \\ College of Engineering, University of Al-Qadisiyah,Al-Qadisiyah, Iraq \\ Email: Abbas.Shuaab@qu.edu.iq;dr_abbas_k@yahoo.com \\ Nawras Shareef SABEEH, \\ College of Engineering, University of Al-Qadisiyah,Al-Qadisiyah, Iraq \\ E mail: Nawras.Sabeeh@qu.edu.iq
}

\begin{abstract}
Adsorption and desorption kinetic curves for equimolar hydrogen - methane mixture on molecular sieve type $5 A$ were experimentally obtained for pressure range 0.122 - 3.546 MPa.The linear driving force rate expression model was used to simulate the dynamic of adsorption and desorption in adiabatic fixed bed adsorber. The model takes into account the interference effects for non-linear isotherms and non-isothermal system. The equations were solved by backward finite difference method with a fixed gridding technique. The individual mass transfer parameters were obtained by matching the theoretical with the experimental data and found to be equal to $8.510 \mathrm{~s}^{-1}$ and $0.783 \mathrm{~s}^{-1}$ for hydrogen and methane, respectively. The predicted effluent histories were shown to be in close agreement with the experimental data for the system. The lowest relative capacity of the bed for methane was almost approximately 95\% of that predicted equilibrium capacity. The predicted temperature profiles tracked the experimental temperature data points, but with higher values. Furthermore, the maximum temperature increasing was observed for the adsorption of methane onto $5 \mathrm{~A}$ molecular sieve at 35 atmospheres and was recorded as $44 \mathrm{~K}$.
\end{abstract}

Keywords: Hydrogen, Methane, Sorption, Kinetics, 5A Molecular Sieve.

\section{NOMENCLATURE}

Symbol
$a_{1}, a_{2}, a_{3}, a_{4}$
$d_{i}, d_{0}$
$h_{w}$
$k_{G i}$
$q_{i}, q_{j}$
$q_{m}$
$q^{*}$
$T$
$U$
$y_{i}, y_{j}$

Page 396

\section{Notation}

Langmuir isotherm coefficients

Inner, outer diameter of adsorption column

Wall heat transfer coefficient

Mass transfer parameter for component $i$

Adsorbed phase concentration of component $i, j$

Monolayer adsorbed phase concentration

Adsorbed phase concentration at equilibrium

Time

Superficial gas velocity

Mole fraction in gas phase for component $i, j$
$\underline{\text { Unit }}$
$\bar{M}$
$\mathrm{W} \mathrm{m}^{-2} \mathrm{~K}^{-1}$
$\mathrm{s}^{-1}$
mole $\mathrm{g}^{-1}$
mole $\mathrm{g}^{-1}$
mole $\mathrm{g}^{-1}$
$\mathrm{S}$
$\mathrm{m} \mathrm{s}^{-1}$

- 


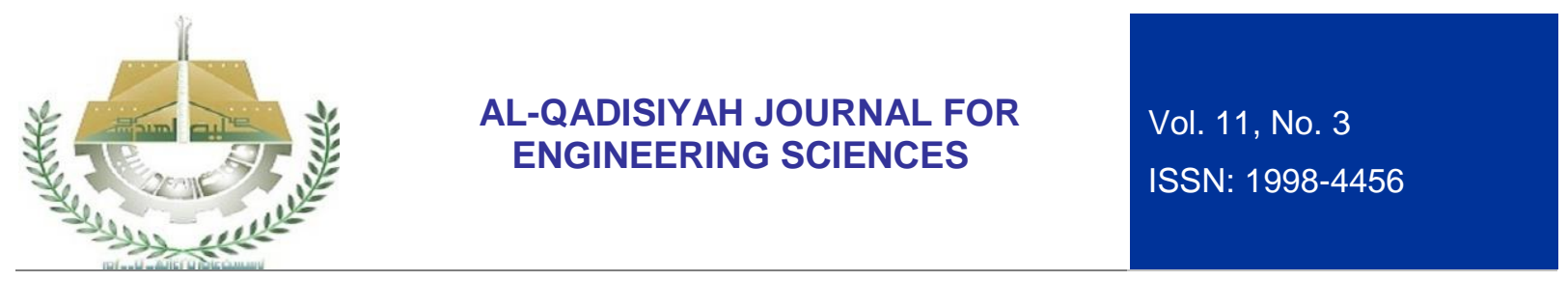

$\begin{array}{ll}Z & \text { Axial coordinate } \\ B_{i}, B_{j} & \text { Adsorption coefficient in Langmuir equation for component } i, j \\ C p_{g}, C p_{p}, C p_{w} & \text { Thermal capacity of gas phase, particles and wall, respectively } \\ F & \text { Relative error coefficient } \\ L & \text { Packed bed length } \\ N & \text { Number of experimental data points } \\ P & \text { Absolute pressure } \\ T_{g}, T_{w} & \text { Absolute temperature of gas phase and wall, respectively } \\ \varepsilon_{t} & \text { Total void fraction of the packed bed } \\ \rho_{b}, \rho_{g}, \rho_{w} & \text { Density of packed bed, gas phase and wall, respectively } \\ \Delta H_{j} & \text { Heat of adsorption for component } j\end{array}$

M

$\mathrm{Pa}^{-1}$

$\mathrm{J} \mathrm{mole}^{-1} \mathrm{~K}^{-1}$

$-$

$\mathrm{m}$

$\mathrm{Pa}$

K

$\mathrm{kg} \mathrm{m}^{-3}$

$\mathrm{J} \mathrm{mole}^{-1}$

\section{INTRODUCTION}

In the not too distant past, any hydrogen byproduct of an operation plant was vented, flared or grudgingly used as a fuel. Recently, a combination of factors has substantially increased its utility as a raw material. Petroleum refiners are forced to use sour crude, which must be hydro-treated; chemical manufacturers are asked to supply more and more ammonia for fertilizer. These and other applications have increased total domestic hydrogen consumption [1].

Five types of processes were found in literature for separation of hydrogen from gas mixtures. These processes include: condensation, absorption, diffusion, adsorption and electrochemical separation [1, 2]. The last fifty years have testified an enormous growth of gas adsorption processes that has made adsorption system a major tool for purification and for separation in chemical, biochemical and petroleum industry. The propagation is an outcome of a spectrum of scientific and engineering developments. This was launched by the discovery of synthetic molecular sieve zeolite and the adsorption cycles. These inventions followed by a progression of technical and theoretical improvements. The main advantages of adsorption as a separation technique, compared with the other processes are that in considerable situations higher selectivity can be gained by adsorption than by any of the another techniques, and adsorbents have a comparatively high capacity for volatile substances, even at little partial pressures. The characteristic of high selectivity covenants more efficient separation while high capacity permits the usage of higher temperature and lower pressure [3].

Gas adsorption operations comprise the eclectic adsorption of one or more ingredients of a gas at the surface of micro-porous solid. Physical adsorption is usually pronounced in separation processes. Therefore, by increasing the temperature of the adsorbent or reducing the adsorbate partial pressure, the adsorbate can be desorbed. Desorption permits retrieval of adsorbates in those separation processes where they are worthy and it allows reusing of the adsorbent for more cycles [4]. The adsorption technique is well-suited to provide high purity hydrogen because of the great selectivity difference between hydrogen and other components such as $\mathrm{CO}_{2}, \mathrm{CH}_{4}$ and $\mathrm{CO}$ on solid adsorbents. particularly activated carbon and molecular sieves were usually used [5]. It was found in our earlier work that 5A Molecular Sieve has better adsorption characteristics than Activated Carbon in the capacity, heat of adsorption, affinity and selectivity [6].

Dynamic data are needed to avoid excessive laboratory and pilot plant facilities. To obtain such data, adsorption models are used to predict it. Large numbers of researchers have studied the issue, and the solution that has been acquired can be in general categorized into two kinds: the equilibrium and the nonequilibrium theories [7]. Equilibrium case may attained if a pure non-porous adsorbent surface was bared to a gas and the boundary layer neighboring to the surface gave no resistance to transfer of gas to the surface. Physical adsorption at a surface is virtually instantaneous so that the rate of adsorption in a micro-porous adsorbent is almost invariably controlled by diffusional resistance to mass transfer rather than by the intrinsic surface kinetics [8]. There is a formidable body of literature dealing with the solution of fixed bed equations for non-equilibrium operation. Two general approaches can be discerned. The first is deductive approach; the relevant mechanisms of transfer are picked out and combined to give a rate equation. The second is inductive in the sense that a solution is used which has been found for a particular kind of rate expression. 


\section{AL-QADISIYAH JOURNAL FOR ENGINEERING SCIENCES}

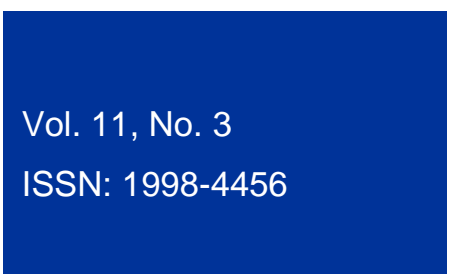

The actual conditions of operation for which the solution is required are then arranged in the form of this rate expression [9].

Analytical solutions of the adsorption process exist in a few special cases only. Graphical solutions have occasionally been utilized to evaluate the result of a single and multi-component adsorption process. However, when an exact prediction is necessary, the numerical methods remain to be the means only. This is predominately valid for a multi-component process with diversified mass and heat transform conditions [10]. Essentially, three kinds of numerical methods have been utilized to solve numerical simulations of the non-equilibrium multi-component adsorption processes: the characteristics method, the orthogonal collocation method and finite difference method [11]. The finite difference method is extremely used due to its efficiency, simplicity in solving parabolic and hyperbolic equations and simple of modifying initial and boundary conditions [4]. The finite difference methods can be classified to implicit and explicit methods. Although explicit methods are non-iteration, they are less accurate and usually require more time for computations due to the limiting stability. The implicit method yields elevated accuracy and it is stable for any case [11].

The objective of the present study is to derive a general mathematical model of gas separation by adsorption process and to show how this model can successfully be used to analyze typical hydrogen recovery processes. The system of partial differential balance equations along with the equilibrium and rate relationships with the relevant initial and boundary conditions were solved for adsorption and desorption steps.

The calculations reveal that the model provide a rather valid description, both quantitative and qualitative, of the complex hydrogen separation processes differing in the values of operating variables. The model can thus be used in designing new and optimizing the already operating adsorption installations. Also, it can be of tremendous help in illustrating the relative importance of the various parameters involved in adsorption processes.

\section{EXPERIMENTAL WORK}

The apparatus was designed for experimentally simulating the adsorption and desorption processes, and qualified for extensive range of operating conditions (adiabatic, high temperature, pressure and flow rate, etc.) for bulk gas separation. The equipment was controlled and automated, with the only manual steps being the samples analysis and the flow rates and pressure recording.

A schematic diagram and photographic picture of the equipment are shown in figures 1 and 2 , respectively. The sorption column was a stainless steel pipe $33 \mathrm{~mm}$ internal diameter and $670 \mathrm{~mm}$ long. Fine mesh gauze plate and a stratum of glass wool are putted at the two ends of the column to catch adsorbent in position and prohibit heat loss from bed ends. All lines were $1 / 8$ inch (3.2 $\mathrm{mm}$ O.D. and $2.4 \mathrm{~mm}$ I.D.) stainless steel. Three solenoid valves (J. Burnham comp. Ltd. Type 18/30-K) placed at the upper, lower and feed points were utilized to change the direction of flow in and out of the column. These valves were controlled by electrician timers. They were set to work at desired period of times. A check valve was putted in the purge line to prevent any back flow. The purge line was regulated by two regulators connected in series. A pressure gauge (Gallenkamp ARIC) was placed at the head of the column to read the pressure history of the process.

An insulation layer of glass wool wrapping the column makes the variation of temperature in the radial orientation as little as possible. The insulation layer also simulates adiabatic condition which approximates industrial adsorption processes when wide diameter columns are utilized.

The axial distribution of temperatures were recorded and measured via multiple channels digital recorder (Dacq TR-2721) at top, middle and bottom locations of the bed. This was accomplished by three downy thermocouples (1/16 inch) covered by a small (1/8 inch) safeguard pipe of copper which was inserted to the midst of the adsorption column. 


\section{AL-QADISIYAH JOURNAL FOR ENGINEERING SCIENCES}

Vol. 11 , No. 3

ISSN: 1998-4456

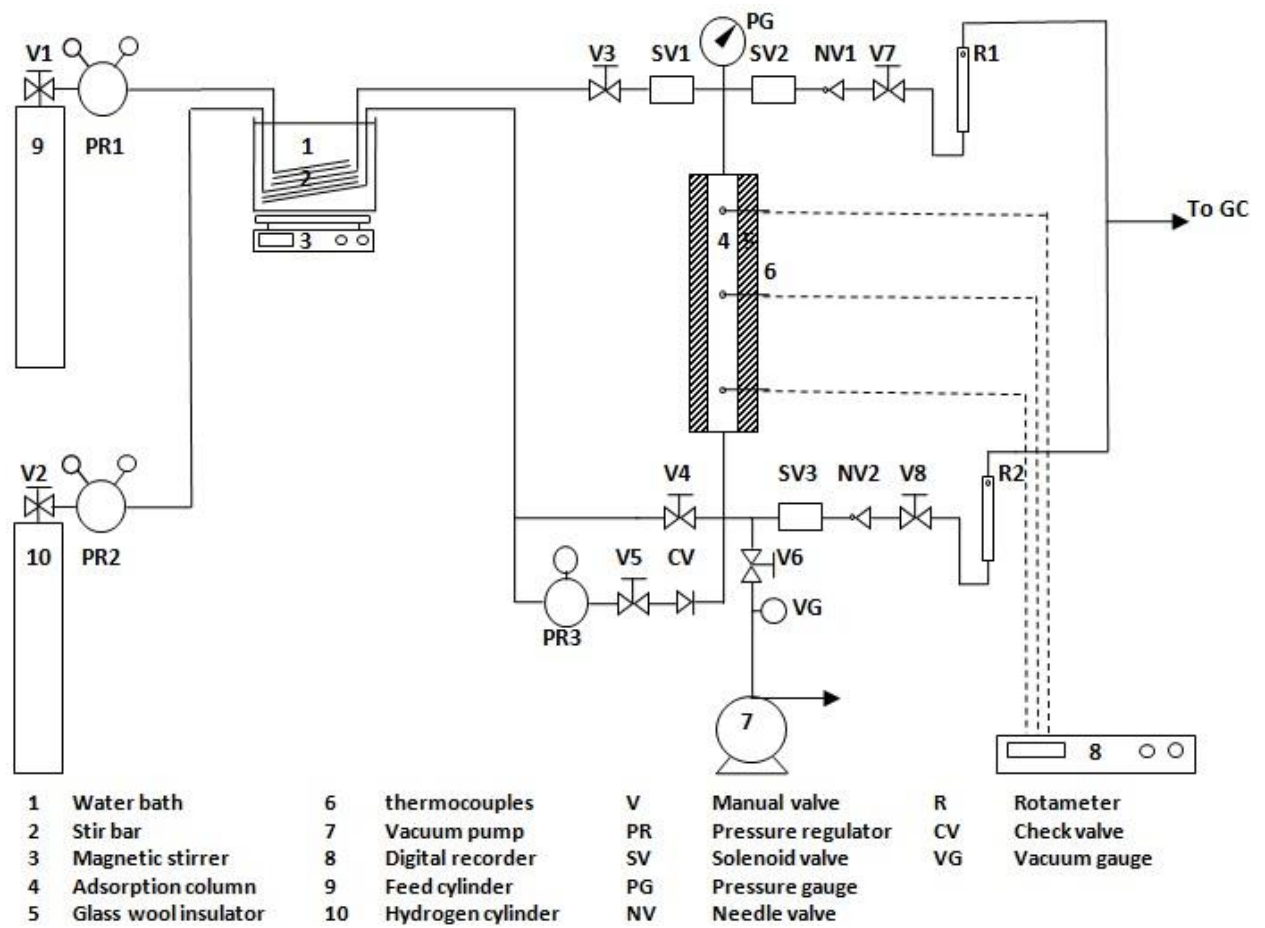

Figure 1. Schematic diagram of apparatus used for sorption kinetics measurements

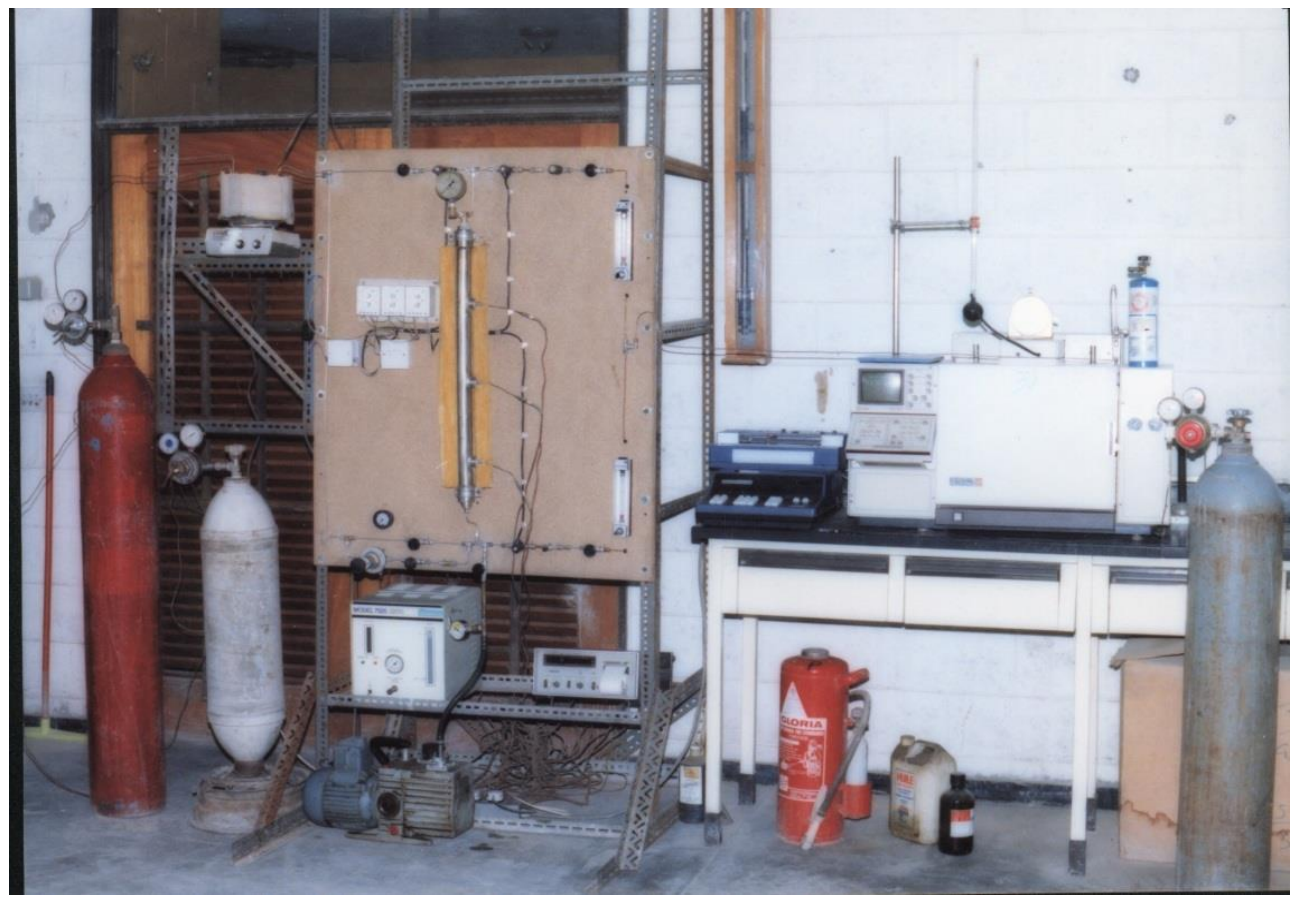

Figure 2. Photographic picture of apparatus used for sorption kinetics measurements 


\section{AL-QADISIYAH JOURNAL FOR ENGINEERING SCIENCES}

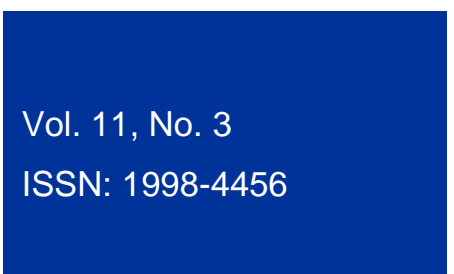

The intake gases pipes were coiled (approximately $200 \mathrm{~cm}$ long) and immersed in a water bath to preheat the gas streams. The output flow rates were regulated by two needle valves (Micro-Hooke mite) and monitored by two rotameters (GEC-Elliott, Ltd.).

Prior to each experiment, the commercial grade 5A molecular sieve (Rhone Poulenc industries Itd.) was regenerated by a vacuum oven (Gallenkamp) which was operated at $10 \mathrm{kPa}$ pressure and $373 \mathrm{~K}$ temperature for overnight, in order to remove previously adsorbed gases from the adsorbent surface.

A weighted specimen of the adsorbent material was packed into the sorption column. A stream of hydrogen was continuously passed through the apparatus for about $120 \mathrm{~min}$ or until the whole adsorbent bed reaches the temperature of the water bath $(303 \mathrm{~K})$. Through this period of time, the gas chromatography unit was switched on and allowed to warm up.

Operation initiated by modifying the intake gas from pure hydrogen to feed gas mixture $\left(49.25 \% \mathrm{H}_{2}-\right.$ $50.75 \% \mathrm{CH}_{4}$ ). At the same time, the outflowing gas concentration and flow-rate were measured. At the latest, the period of time required for the shock-front to navigate the adsorbent column was gained. The gas pressure was adjusted by setting the pressure regulator and the outlet flow rate was adjusted by using a needle valve. At the same time, thermocouples outputs were monitored continuously at three different locations from entrance of the bed to define the temperature breakthrough curves at these positions.

On completion the adsorption run, the mixture supply was cut off. Hydrogen was then supplied to the bed until the adsorbate was completely removed from the adsorbent. Same pressures and flow rates were used for carrying the adsorption and desorption runs.

The effluent from the process was sampled by passing through a $0.5 \mathrm{~cm}^{3}$ sample nub by means of a sampling valve connected to the exhauster. The samples always introduced at atmospheric pressure by a sub-side stream of the effluent gas. The samples were analyzed by using gas-solid chromatographic unit (Varian Vesta, 6000) in accordance with a modified standard test [ASTM D1946-90 (2015)].

\section{MATHEMATICAL WORK}

Predictive model for multi-component gas adsorption is requested in the designing of adsorber and adsorption processes. The magnitude of calculations participated is linked to the grade of complication of these models. Therefore, many reasonable assumptions were introduced to decrease the time and number of computations, also increase the accuracy of solution by decreasing the round-off and truncation errors. The main assumptions based in the emergence of the model are:

1. The operation is adiabatic since the experimental adsorption column is covered with a thick layer of insulator and also to simulate the large diameter adsorbers in industrial applications.

2. The immediate thermal equipoise dominates between the solid and gas materials [12].

3. The longitudinal dispersion in the bed is insignificant for mass and heat. This assumption is based on large Peclet number $(P e)$ accompanying the process [13].

4. The pressure drop across the adsorbent bed is negligible.

5. The velocity profile is flat due to high Reynolds number $(R e)$ and production rate [14].

6. The radial gradient in the bed is negligible for mass and heat [15].

The dynamic behavior of the process when subjected to the above assumptions was described by the following set of equations and appropriate initial and boundary conditions. By taking a differential control volume element of the adsorption column, we get:

Material balance equation for sorbate I (assume ideal gases) in the control volume is:

$$
\varepsilon_{t} \frac{\partial y_{i}}{\partial t}+u \frac{\partial y_{i}}{\partial z}+\frac{\rho_{b}}{\rho_{g}}\left(\frac{\partial q_{i}}{\partial t}-y_{i} \sum_{j=1}^{2} \frac{\partial q_{j}}{\partial t}\right)=0 \quad i=1,2
$$

Energy balance equation in the fluid and solid phases is: 


$$
\begin{aligned}
& \left(\varepsilon_{t} \rho_{g} C p_{g}+\rho_{b} C p_{p}\right) \frac{\partial T_{g}}{\partial t}+\rho_{g} C p_{g} T_{g} \frac{\partial u}{\partial z}+\rho_{g} C p_{g} u \frac{\partial T_{g}}{\partial z}+4 \frac{h_{w}}{d_{i}}\left(T_{g}-T_{w}\right) \\
& -\rho_{b} \sum_{j=1}^{2} \Delta H_{j} \frac{\partial q_{j}}{\partial t}=0
\end{aligned}
$$

Energy balance equation for the packed bed wall is:

$$
\left[\left(\frac{d_{o}}{d_{i}}\right)^{2}-1\right] \rho_{w} C p_{w} \frac{\partial T_{w}}{\partial t}-4 \frac{h_{w}}{d_{i}}\left(T_{g}-T_{w}\right)=0
$$

The equilibrium adsorption isotherm relationships for $i^{\text {th }}$ component in a gas mixture could be expressed by extended Langmuir isotherm equation as follow [6]:

$$
q_{i}=\frac{q_{m i} B_{i} y_{i} P}{1+\sum_{j=1}^{2} B_{j} y_{j} P} \quad i=1,2
$$

The $B$ and $q_{m}$ coefficients count on temperature as follow:

$$
\begin{aligned}
& q_{m}=a_{1} T_{g}^{a_{2}} \\
& B=a_{3} e^{a_{4} / T_{g}}
\end{aligned}
$$

The mass transport rate between the solid and gas in the linear driving force (LDF) model is given by a relationship of the form [7]:

$$
\frac{\partial q_{i}}{\partial t}=k_{G i}\left(q_{i}^{*}-q_{i}\right) \quad i=1,2
$$

It was presumed that the gas composition and pressure in the bed at zero time were known. The walls and gas temperatures are equivalent to the room temperature (pretreatment of the apparatus). At the beginning of desorption step, the concentration profile in the adsorbed and gas phases and the temperature distribution through the column stay the same as those at the termination of the adsorption stage (frozen profiles).

The system of the marching non-linear parabolic partial differential equations, entire with rate and equilibrium relations and the suitable initial and boundary conditions was solved by the implicit backward finite difference procedure with stationary gridding method. The solution was progressed for the adsorption and desorption processes by using Gauss-Seidel iterative method.

The problem variables were described at nub points of network of co-ordinate strips in terms of point samples. Taylor series expansions were utilized to create finite differences approximation of variables derivatives by means of point samples of unknowns at every mish points and its adjacent neighbors. The variables derivatives were exchanged by the finite differences approximation fructifying algebraic equations for the unknowns at every mish point.

Absolute tolerance procedure was used as a convergence tolerance method because it is independent on the scaling of the variable and it is useful if the variable is convergence to any value [16]. This is very important especially for mole fraction determinations before the occurring of shock waves.

The computation was initiated by assuming a set of guessed values for velocity, mole fractions and gas temperature for the segment. The calculations were terminated when the difference of calculated values between two successive iterations is within the tolerance $10^{-3}$ for the velocity and the temperature and within $10^{-4}$ for mole fractions. 


\section{AL-QADISIYAH JOURNAL FOR ENGINEERING SCIENCES}

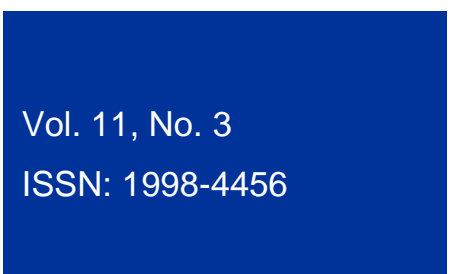

The solution to the system discussed includes the gas and solid concentration profiles and the gas and wall temperature profiles along the column for a number of temporal points. We have used Matlab version 6 (MathWork Inc., Massachusetts) numerical analysis package interactively to solve the equations and plot response curves in this study. The computation time using Pentium III PC was approximately equal to ten minutes for adsorption or desorption process under specified conditions.

\section{RESULTS AND DISCUSSION}

A series of sorption (adsorption-desorption) kinetic curves were obtained experimentally for the system called (Hydrogen - Methane) on 5A molecular sieve. These kinetic curves were matched with predicted kinetic curves in order to characterize and test the model, as well as, to estimate the values of the kinetic parameters which describe the dynamic behavior of adiabatic fixed bed adsorber.

Experimental and theoretical profiles are presented in figures as follow: the $Y$-axis represents the dimensionless concentration ( $\mathrm{y} / \mathrm{y}$ feed $)$ or the dimensionless gas temperature $(\mathrm{Tg} / \mathrm{Tg}$ feed ) while the $\mathrm{X}$-axis

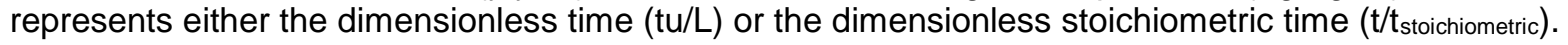

We generated a various adsorption - desorption curves with varying $\mathrm{k}_{\mathrm{Gi}}(\mathrm{s})$ from the numerical solution of the equations of the model. The magnitudes of the parameters correspondent to the conditions of the experiments must be got by matching the theoretical and experimental results. Earlier work [17] shows that the simultaneous matching of sorption results gives an unambiguous calculation of these parameters. The model mass transfer parameters were calculated by minimization of the objective function:

$$
F=\sum_{i=1}^{N}\left(\bar{y}_{i_{(e x p)}}-\bar{y}_{i_{(c a l)}}\right)^{2}
$$

For all the adsorption and desorption experiments, the mass transport parameters for each single component (hydrogen and methane) were calculated separately for each experiment and then rated for all the experiments. Moreover, a procedure based on trial and error was used for parameters determination. The comparison between the theoretically predicted curves and experimentally measured points are shown in figures $3-10$ and the relevant mass transfer parameters were found to be equal to $8.510 \mathrm{~s}^{-1}$ and $0.783 \mathrm{~s}^{-1}$ for hydrogen and methane, respectively.

It is clearly seen that the fit is good enough to conclude that the model results generates an acceptably valid impersonation of adsorption and desorption results. It is also recognized that the fit for adsorption curves are worse than for desorption curves because the rate of desorption was much slower than the rate of adsorption. Hence, more experimental time was required for complete bed cleaning and more experimental data points (30 second time interval was chosen). Therefore, more desorption experimental data points were matched the theoretical curves.

Figures $3-6$ show that the lowest relative capacity of the bed for methane approximately $95 \%$ of that predicted equilibrium capacity. This is because some adsorption active sites of the adsorbent were occupied by hydrogen molecules and to a lesser extent because of rate and thermal effects of adsorption, which may cause early breakthrough. The total pressure increasing has no effect on the relative gas and solid composition for the system $\mathrm{H}_{2}-\mathrm{CH}_{4}-5 \mathrm{~A}$ molecular sieve as shown in our previous work [6]. Therefore, the first reason is the predominant reason because the relative capacity of the bed is almost constant at $95 \%$, while the experiments were conducted at different pressures and flow rates.

The effect of adsorption and desorption pressures on response curves are illustrated in figures $3-10$. It may be seen that the response curves are more diffuse at the higher pressures, as is to be expected on account for the somewhat greater deviation from the rectangular limit. This deviation may be attributed to several reasons. The density of the gas increases with pressure increasing, hence much more mass transfer resistance occurs through bulk gas phase and more diffuse response curves result. The amount of methane adsorbed to achieve equilibrium decreases with pressure decreasing, therefore less gas molecules transfer through the porous adsorbent pellets required to achieve equilibrium. Finally, the much more gas molecules adsorbed at high pressures elaborate more heat of adsorption, then some adsorbed molecules around the shock wave desorb. 


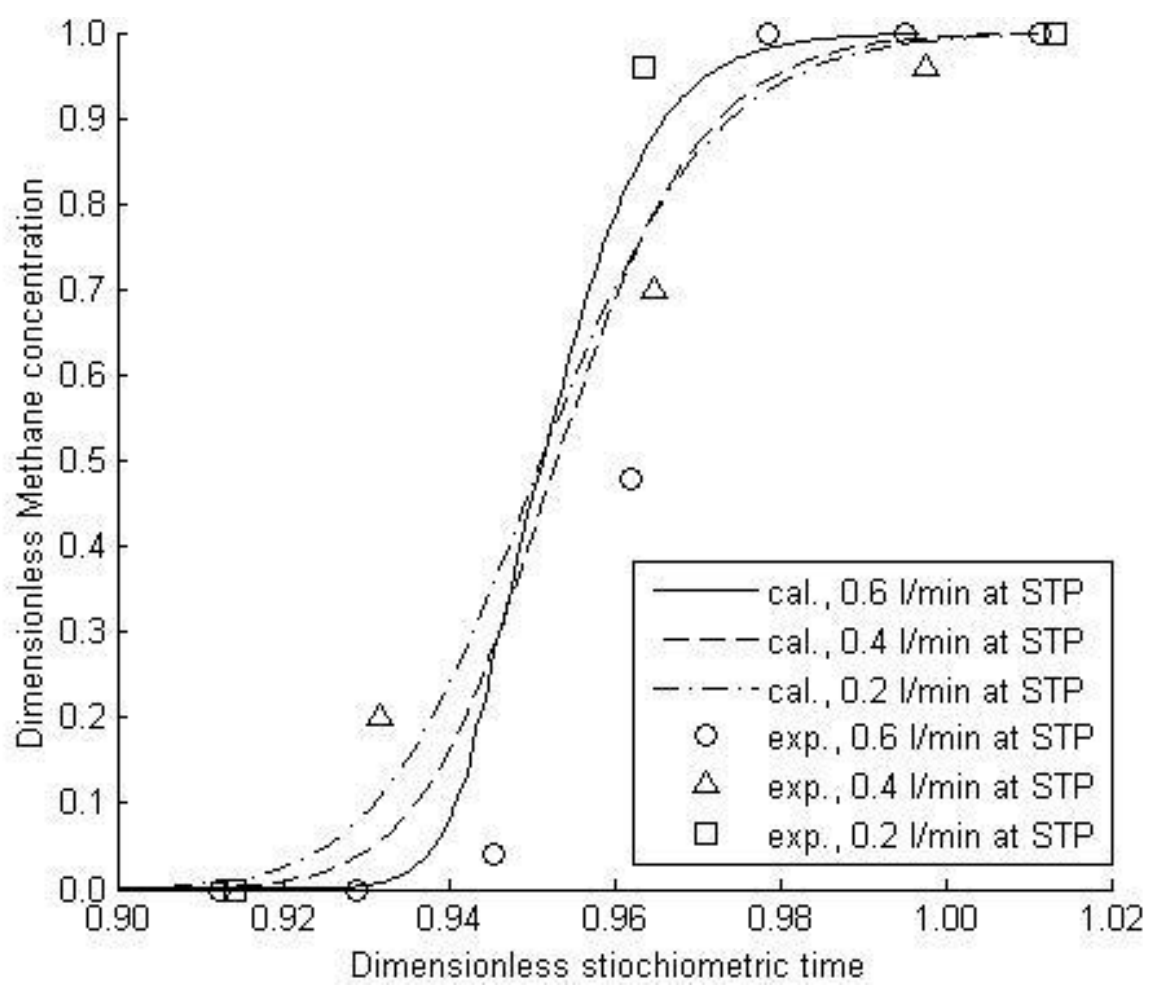

Figure 3. Kinetic of adsorption for the system Hydrogen- Methane-5A Molecular sieve at $1.2 \mathrm{~atm}$

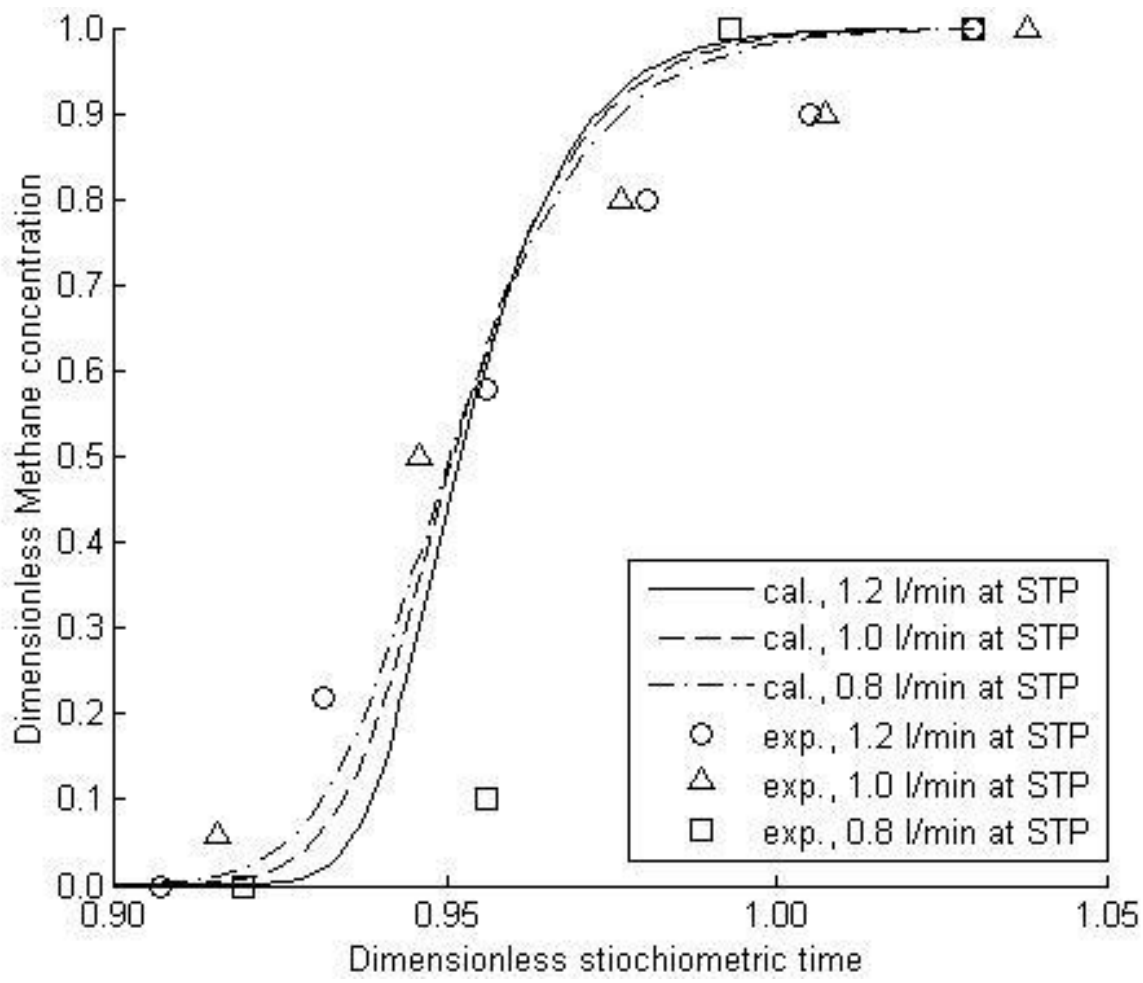

Figure 4. Kinetic of adsorption for the system Hydrogen- Methane-5A Molecular sieve at 5 atm 


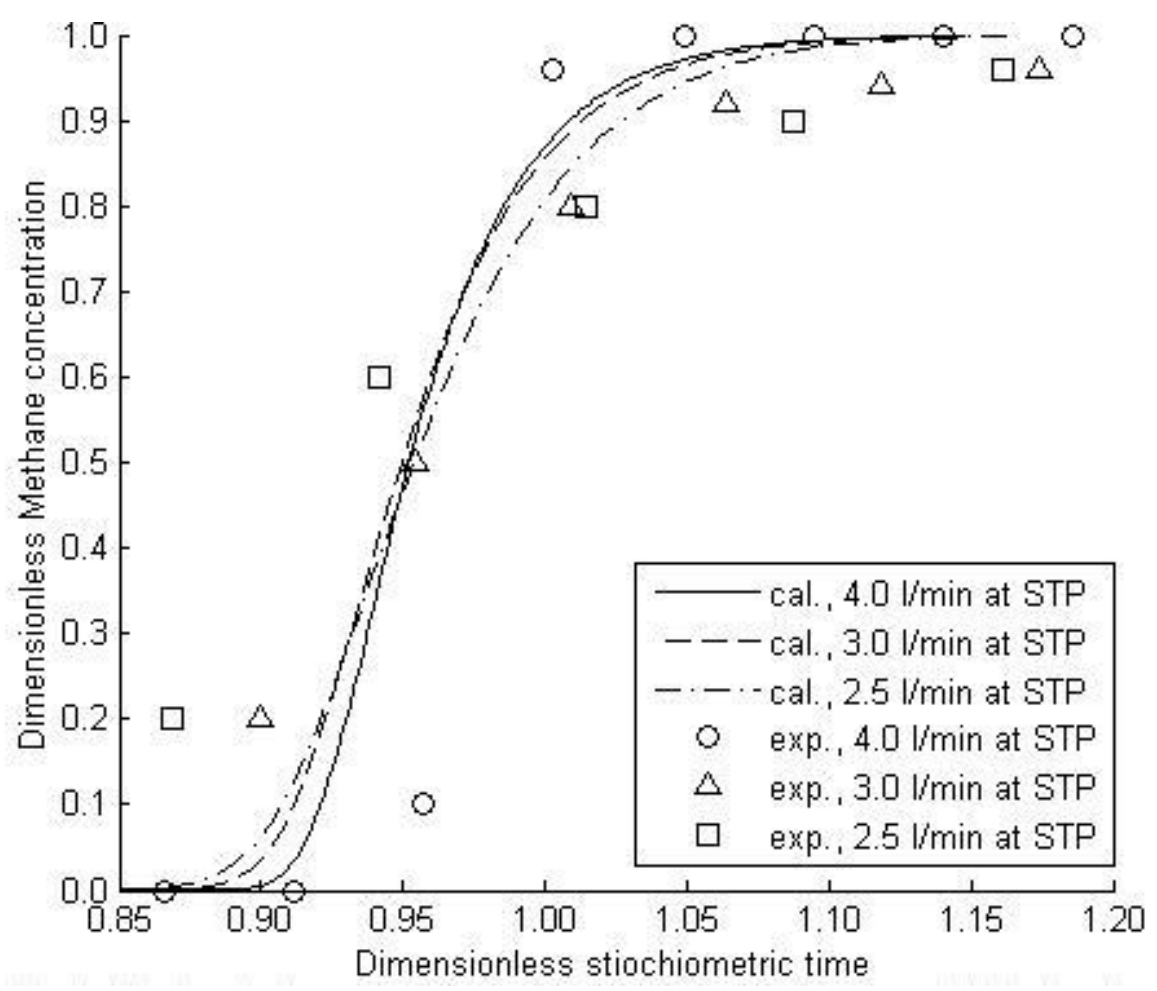

Figure 5. Kinetic of adsorption for the system Hydrogen- Methane-5A Molecular sieve at 20 atm

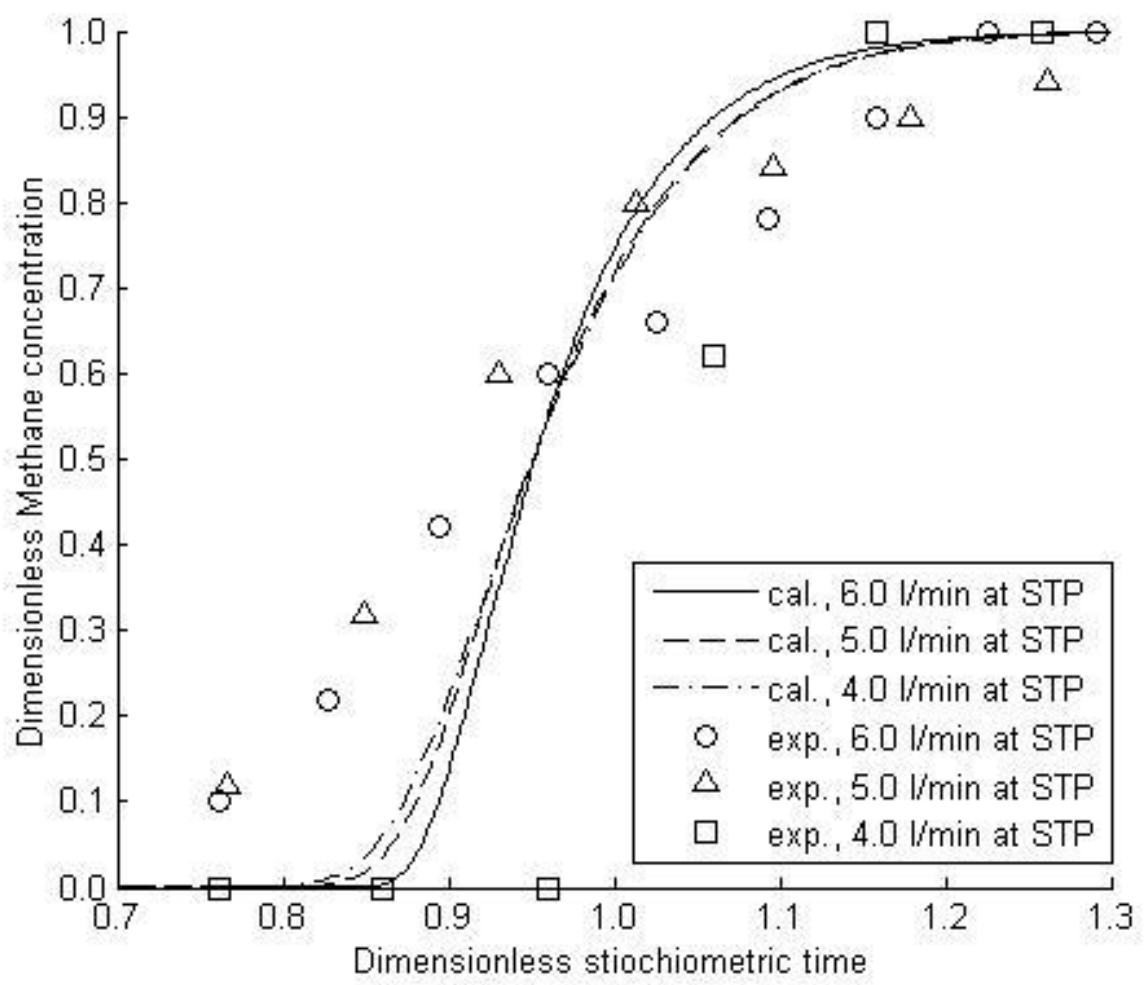

Figure 6. Kinetic of adsorption for the system Hydrogen- Methane-5A Molecular sieve at $35 \mathrm{~atm}$ 


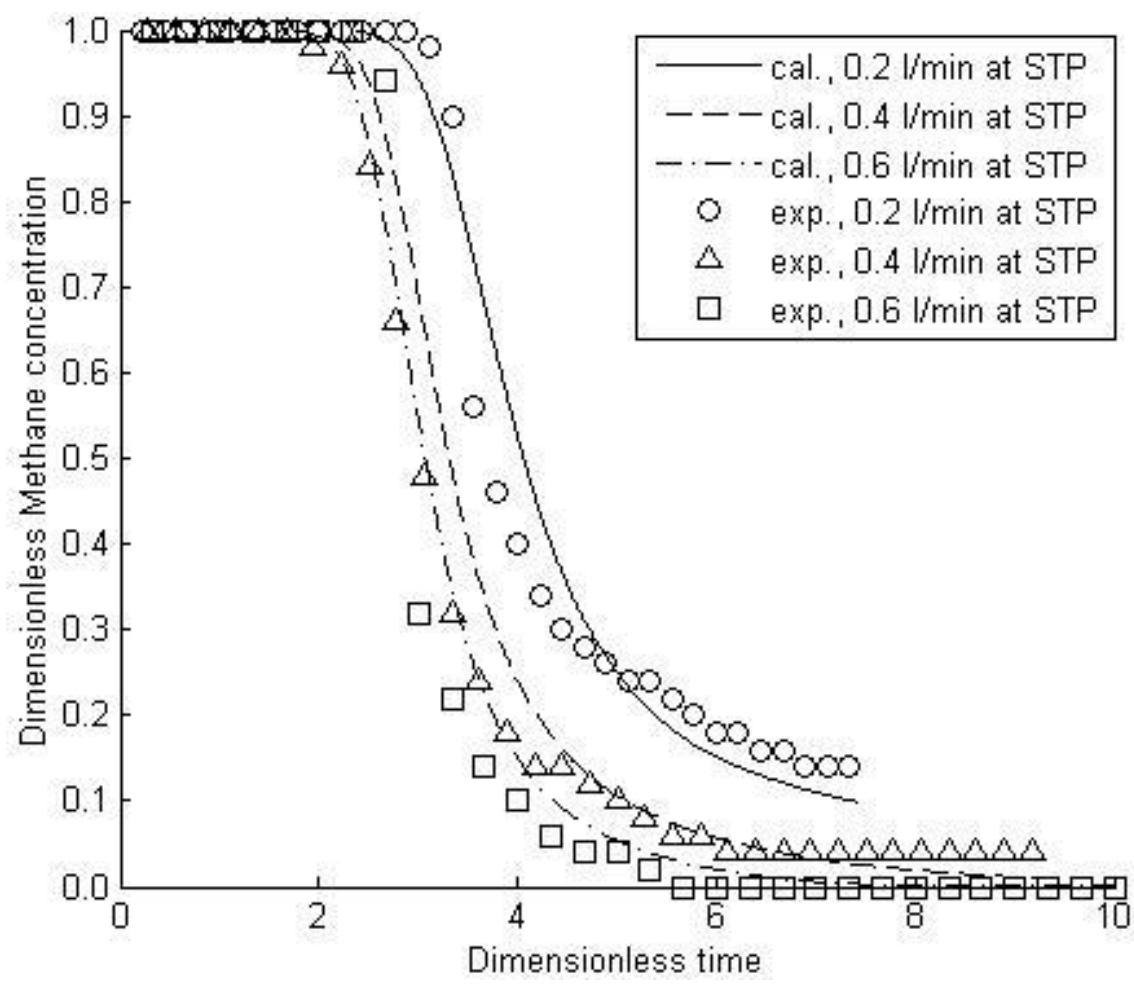

Figure 7. Kinetic of desorption for the system Hydrogen- Methane-5A Molecular sieve at $1.2 \mathrm{~atm}$

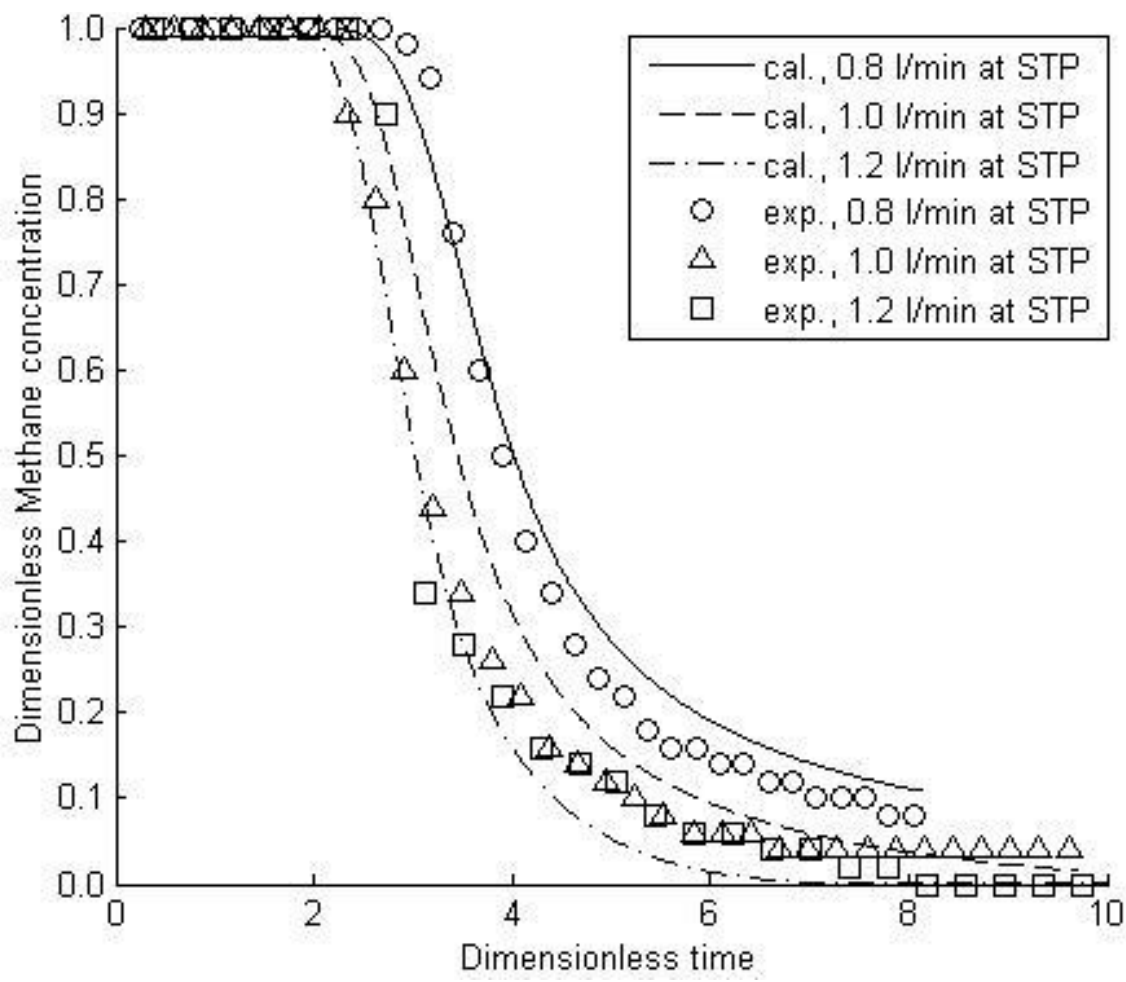

Figure 8. Kinetic of desorption for the system Hydrogen- Methane-5A Molecular sieve at $5 \mathrm{~atm}$ 


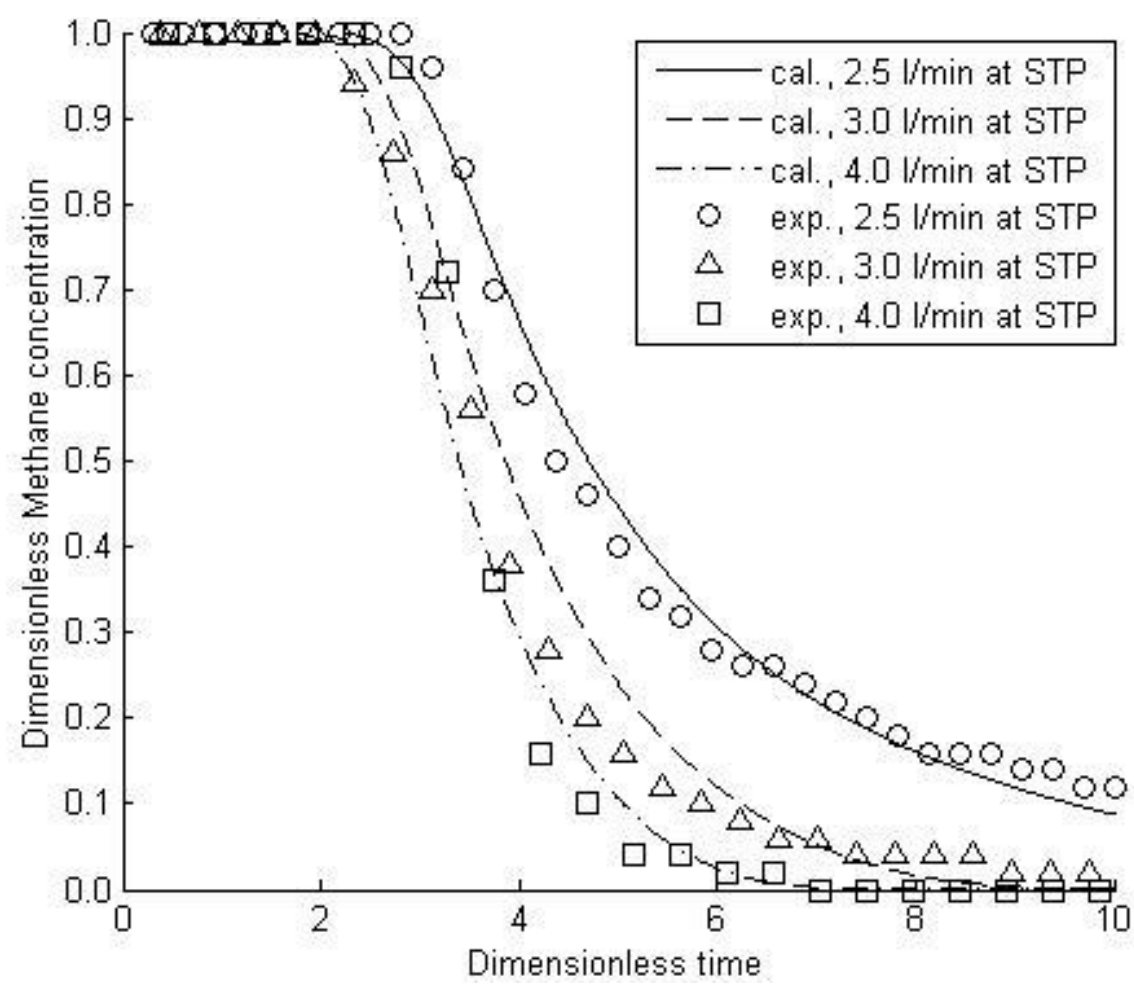

Figure 9. Kinetic of desorption for the system Hydrogen- Methane-5A Molecular sieve at 20 atm

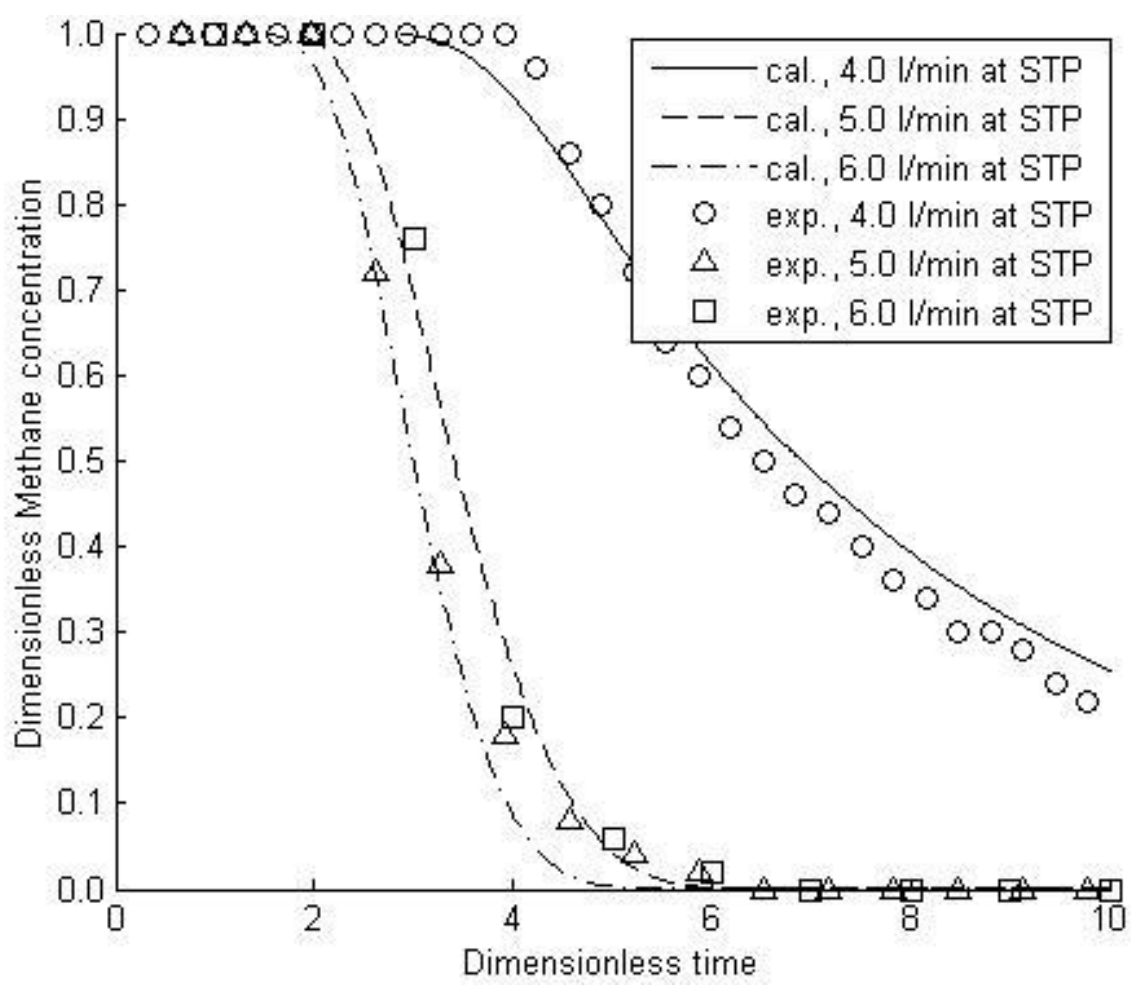

Figure 10. Kinetic of desorption for the system Hydrogen- Methane-5A Molecular sieve at $35 \mathrm{~atm}$ 


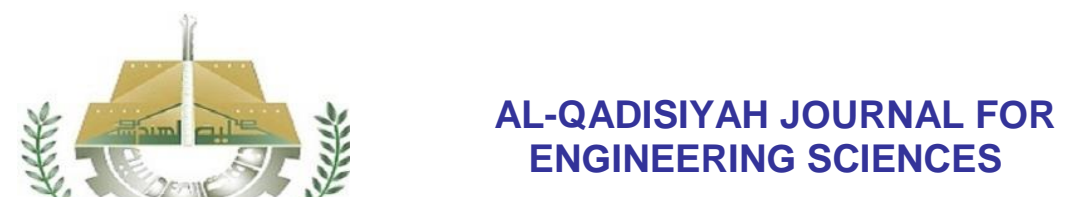

Vol. 11 , No. 3

ISSN: $1998-4456$

Some deviation from the well-known symmetrical (S) shape breakthrough may be noted from figures 3 6 and this deviation increases with pressure increasing. This is because that the second half of the breakthrough curves are more diffuse than the first half of it. This suggests a mechanism other than mass transport might control the rear part of the breakthrough curves is considered as a temperature control part. This result is in agreement with earlier work [18].

The effect of product flow rate on the response curves is clearly noticed from observing figures $3-6$. It was noticed that a slower gradients were obtained with a slower flow rates, because mass transfer resistances increase with flow rate decreasing.

In figures 11 and 12 the kinetic and thermal curves at three axial positions in the column are shown. From the first figure, it was recognized that the concentration wave fronts become more and more diffuse as the bed length increases. This is may be attributed to the diffusion resistances which prevent rapid uptake and cause an early and more diffuse breakthrough curve of methane. The temperature curves demonstrate the importance of heat of adsorption in the adsorptive separation processes. There are significant rises of system temperature due to relatively high concentrations of adsorbates used, as shown in figure 12 .

The maximum temperature increasing was observed for the adsorption of methane onto $5 \mathrm{~A}$ molecular sieve at 35 atmospheres and was recorded as $44 \mathrm{~K}$. Hence, the heat balance equations are necessary for the prediction of response curves, otherwise, large deviation may be obtained. Furthermore, thermal effects were expected to be larger for the adsorption of higher hydrocarbons, since these compounds have higher heat of adsorption.

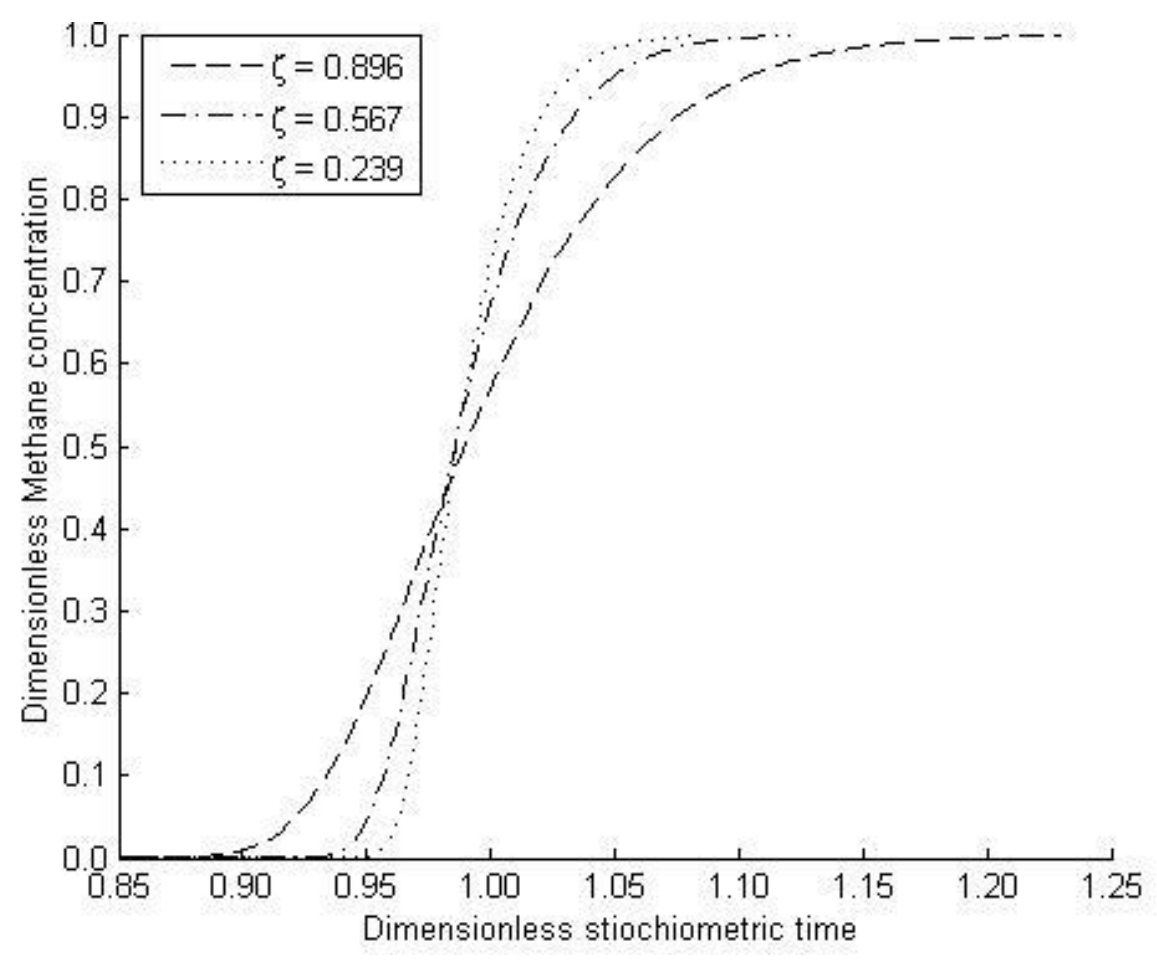

Figure 11. Concentration distribution for the system Hydrogen- Methane-5A Molecular sieve at $35 \mathrm{~atm}$ and $5 \mathrm{l} / \mathrm{min}$ at STP 

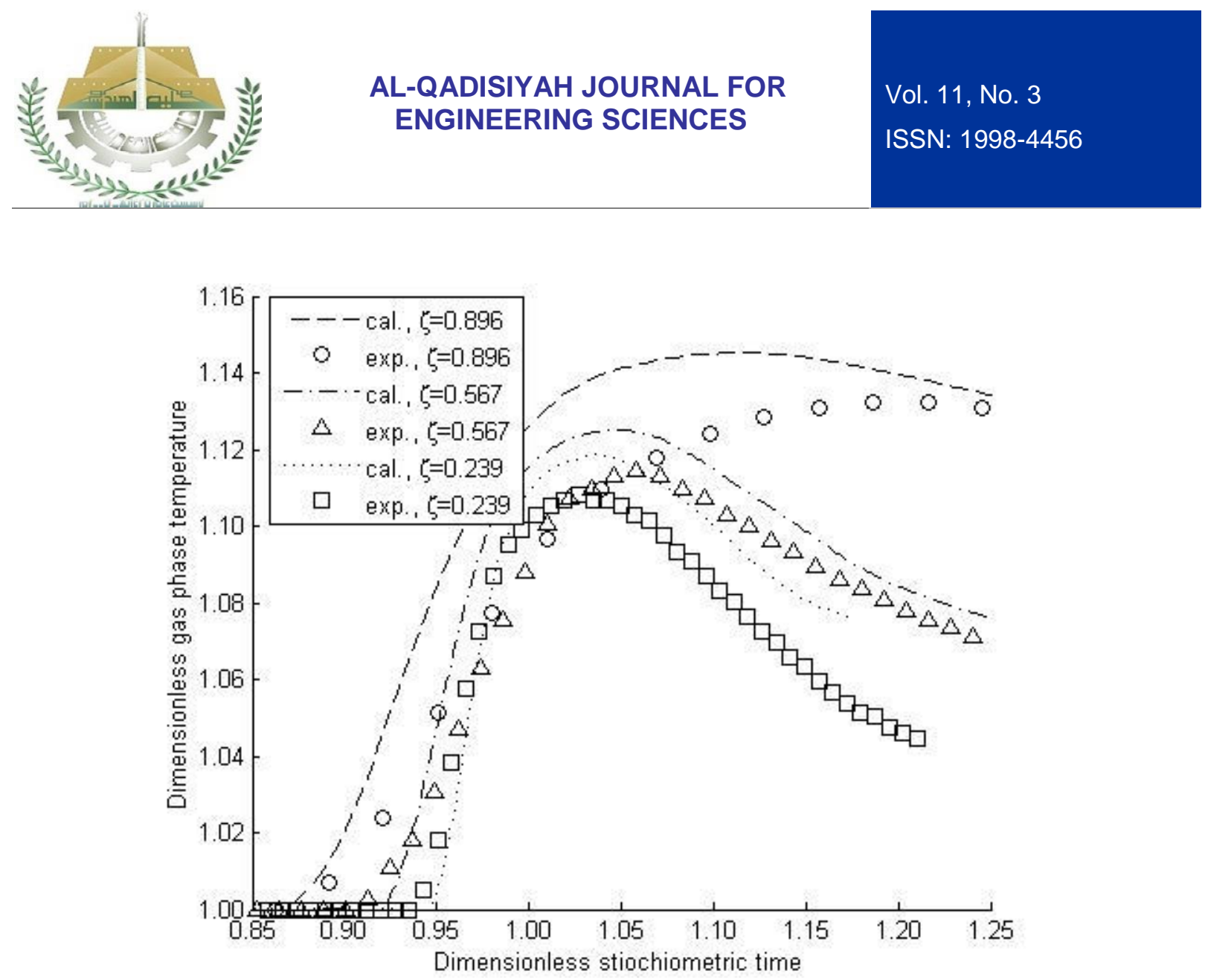

Figure 12. Temperature distribution for the system Hydrogen- Methane-5A Molecular sieve

\section{at $35 \mathrm{~atm}$ and $5 \mathrm{l} / \mathrm{min}$ at STP}

The predicted temperature profiles tracked the experimental temperature data points, but with higher values. These variations could be elucidated as follows. The model was neglected the effects of axial heat conduction through the column wall and radial heat conduction. These parameters might be important in the experimental equipment used in this study. Furthermore, the heat liberated from adsorption is function of coverage of adsorption surface. This final effect was also neglected in the model equations by assuming constant heat liberation through the whole range of operation.

The temperature profiles rises approximately simultaneously with the concentration breakthrough curves because the elaborations of heat and methane adsorption are simultaneous phenomena. Therefore, the system temperature at lower axial position rise sharply as concentration do, this is because the heat liberated by methane adsorption. The cooling zone moves very slowly and with comparatively tiny inclination through the column. The inclination of the cooling wave front becomes steeper with a detraction height of the column. This is because that the convective stream holds the excess heat from the forward part of the bed to the rear cold part, then more diffuse response curves produced.

\section{CONCLUSIONS}

1. The model obtained in this study gives an adequate characterization of the breakthrough of the hydrogen-methane mixture on $5 \mathrm{~A}$ molecular sieve.

2. Increasing in pressure or decreasing in flow rate give more diffuse breakthrough curves for the system of hydrogen-methane on $5 \mathrm{~A}$ molecular sieve.

3. The total pressure increasing has no effect on the relative gas and solid composition for the system $\mathrm{H}_{2}-\mathrm{CH}_{4}-5 \mathrm{~A}$ molecular sieve and the lowest relative capacity of the bed for methane approximately $95 \%$ of that predicted equilibrium capacity.

4. Heat balance equations are necessary for the prediction of response curves due to relatively high concentrations of adsorbates used, which cause a significant rise of system temperature. 


\section{BIODATA}

- Abbas Khalaf MOHAMMAD is Associate professor at College of Engineering, University of Al-Qadisiyah, Al-Qadisiyah, Iraq.

- Nawras Shareef SABEEH is Lecturer at College of Engineering, University of Al-Qadisiyah, Al-Qadisiyah, Iraq.

\section{REFERENCES}

1. Rabiei, Z. Hydrogen management in refineries, „Petroleum and Coal", 54 (4), 357 (2012).

2. Oztek, M.T. Recovery of hydrogen and helium from their mixtures using metal hydrides, M.Sc. thesis, University of Central Florida (2005).

3. Mohammed, R.R. Separation of multi-components gas mixtures by adsorption, Ph.D. thesis, University of Technology (1996).

4. Huang, C.C.; Fair, J.R. Study of the adsorption and desorption of multiple adsorbates in a fixed bed, „AIChE J.", 34, 1861 (1988).

5. Cassidy, R.T.; Holmes, E.S. Twenty-five years of progress in adiabatic adsorption processes, „AIChE Symp. Ser.", 80, 68 (1984).

6. Mohammad, A.K.; Sabeeh, N.S. Comparative study for adsorption of hydrogen-methane mixture on activated carbon and 5A molecular sieve, „Braz. J. Chem. Eng.", 35 (2), 795 (2018).

7. Shafeeyan, M.S.; Daud, W.M.A.W.; Shamiri, A. A review of mathematical modeling of fixed-bed columns for carbon dioxide adsorption, „Chem. Eng. Res. Des.", 92, 961 (2014).

8. Carberry, J.J. Chemical and catalytic reaction engineering, Dover publications Inc., Mineola, New York (2001).

9. Richardson, J.F.; Peacock, D.G. Coulson and Richardson's Chemical engineering, Vol. 3, 3rd ed., Butterworth-Heinemann, Oxford (2007).

10. Rodrigues, A.E., LeVan, M.D.; Tondeur, D. Adsorption: Science and technology, Springer, Netherlands (2011).

11. Holland, C.D.; Liapis, A.I. Computer methods for solving dynamic separation problems, McGrawHill, New York (1983).

12. Banerjee, R., Narayankhedkar, K.G.; Sukhatme, S.P. Exergy analysis of pressure swing adsorption processes for air separation, „Chem. Eng. Sci.", 45, 467 (1990).

13. Farooq, S., Ruthven, D.M.; Boniface, H.A. Numerical simulation of a pressure swing adsorption oxygen unit, „Chem. Eng. Sci.", 44, 2809 (1989).

14. Farooq, S., Hassan, M.M.; Ruthven, D.M. Heat effects in pressure swing adsorption systems, „Chem. Eng. Sci.", 43, 1017 (1988).

15. Yang, R.T.; Cen, P.L. Improved pressure swing adsorption processes for gas separation, „Ind. Eng. Chem. Process Des. Dev.", 25, 54 (1986).

16. Bequette, B.W. Process dynamics: Modeling, analysis and simulation, Prentice Hall, New Jersey (1998).

17. Pontikakis, G., Papadimitriou, C.; Stamatelos, A. Kinetic parameter estimation by standard optimization methods in catalytic converter modeling, „Chem. Eng. Comm.", 191, 1473 (2004).

18. Kasser, N.W. Dynamic behavior of non-isothermal multi-component adsorption in adiabatic fixed bed, Ph.D. thesis, University of Baghdad (1997). 